\title{
swiss economics
}

\section{Defending Mail Markets against New Entrants: An Application of the Defender Model}

\author{
Christian Jaag \\ Helmut Dietl \\ Urs Trinkner \\ Oliver Fürst
}

Swiss Economics Working Paper 0027

July 2011

ISSN 1664-333X

Published as:

“Defending Mail Markets Against New Entrants: An Application of the Defender Model” (2012). In: Multi-modal Competition and the Future of Mail. Crew, M. A. and Kleindorfer, P. R. (eds), pp. 236-246.

Swiss Economics SE AG

Stampfenbachstrasse 142

CH-8006 Zürich

T: +41 (0)44 5005620

F: +41 (0)44 5005621

office@swiss-economics.ch

www.swiss-economics.ch 


\section{INTRODUCTION}

Market positioning has long been an intensely discussed topic in the economics and marketing literature. Until the early 80s, the literature mainly tackled the issue of optimal new brand positioning. Existing brands thus had an idea of how a new brand might attack. The reverse question of how to optimally defend its market share and profit against an attack remained unanswered until Hauser and Shugan (1983). In their original paper, "Defensive Marketing Strategies," Hauser and Shugan introduced a model that goes beyond the traditional analysis of offensive new-brand positioning by focusing on the defending rather than the attacking brand ("defender model").

One basic observation of the authors was that in most markets incumbents react to competition by lowering prices. In some industries, however, established firms defend their profits against market entrants by increasing product prices. These differences are explained by heterogeneous consumer preferences. Hauser and Shugan modeled this heterogeneity with a continuous distribution of consumer tastes. Another key assumption of their model is the 'per-dollar' measure of product utility. Instead of integrating price as a separate dimension in a traditional perceptual map (such as Urban and Hauser, 1980; Hauser and Gaskin, 1984), the authors plotted each quality dimension in relation to the product's price as proposed by Hauser and Simmie (1981).

From the model, qualitative normative implications on how established firms should defend their profits when facing an attack by a new competitive product can be derived. Hauser and Shugan did not limit the scope of strategic instruments to the dimension of price. They allowed for incumbents to react by adjusting distribution and awareness advertising expenditures, budgets for repositioning advertising, and product quality improvements. The main recommendations were that prices are to be decreased in non-segmented markets and potentially increased in highly-segmented markets; distribution and awareness advertising expenditures should be lowered while budgets for repositioning advertising and product improvement 'away' from the strengths of the new products should be increased.

The model and its results have since been verified empirically for several industries, such as food, software and pharmaceuticals, cf. Hauser and Gaskin (1984) and Kuester et al. (2001). While the defender model predicts the optimal direction of response, later empirical studies in the field of defensive strategies examined further aspects of defensive actions, such as the reaction speed and the intensity of reactions. MacMillan et al. (1985) find that reaction speed increases in the threat posed by the attacker and decreases in the size of the defending brand. ${ }^{1}$ A high reaction speed has been examined in markets with high growth rates and low switching costs, e.g. by Bowman and Gatignon (1995).

Other studies focus on the intensity of the defending brands' reactions. These studies find that the intensity of reactions increases in the threat posed by the attacker and in market size 
and growth, cf. Heil and Walters (1993) and Shankar (1999). The incumbent's market dominance and the extent of the attacker's investments have been identified as being negatively correlated to reaction intensity, e.g. by Shankar (1999). Kuester et al. (2001) summarize the most relevant studies in the field of defensive strategies: Reaction speed and intensity are highest in highly concentrated and growing markets, while size and innovation capabilities of the attacking firm have negative effects on the defending firm's reaction intensity. The empirical significance of the model is demonstrated by Hauser and Gaskin (1984) and Shugan (1987) who apply the defender model to different markets. Shugan (1987) concludes that "[their] model fits well and provides potentially useful information" (p. 14) and Hauser and Gaskin posit that "the defender model is an adequate representation of aggregate consumer response" (p. 347). Nevertheless, the success of each application highly depends on the choice of attributes (see Hauser and Shugan, 2008).

The objective of this contribution is to apply the defender model to the postal market, which is increasingly opened up to competition in many countries. There is a limited literature on competitive entry strategies in postal markets. Based on a game-theoretic model and interviews with market participants, Dietl and Waller (2002) argue that competition in letter markets will mean new services and lower, but differentiated prices. While businesses and customers in urban areas will benefit from price decreases, households and rural areas will face higher prices. New business models such as mass mail providers, networked mail services, and consolidators with differentiated service propositions will emerge, targeting selected segments of the market. Incumbents will have to significantly change their behavior, become more efficient, and tailor their services to individual needs.

Cohen et al. (2007) discuss the impact of competitive entry into the Swedish postal market. They find that almost immediately after CityMail, the first competitor in the Swedish market for mail, entered the market, Sweden Post began to adjust its pricing structure by introducing discounts for bulk and presorted mail. Posten's bulk mail price has decreased (unlike single-piece), reflecting the intense competition from CityMail.

The interaction between competition and (Universal Service) regulation has been studied, (Crew and Kleindorfer 2001, 2007). Dietl et al. (2005) and Jaag (2007) provide applications to the mail market in Switzerland. Kleindorfer and Szirmay (2009) review pricing practices of incumbent postal operators in Europe in the context of liberalization, but they also note the rudimentary state of marketing practices and capabilities in many of these operators.

While the studies mentioned above focus on the need for incumbents to adjust prices as a result of competitive entry (and still being restricted by Universal Service Obligations), our contribution assesses the possibility of reacting by a Universal Service Provider (USP) by adjusting its overall value proposition accordingly, including non-price product attributes. 
The remainder of this paper is organized as follows: Section 2 describes the basic model and its assumptions. In section 3, we deduce revenue-optimal pricing and product differentiation strategies by simulating different attacks. Section 4 concludes.

\section{THE MODEL}

\subsection{CUSTOMER PREFERENCES}

Our model of customer preferences follows the main assumptions of the original model. ${ }^{2}$ Every customer in the market maximizes his or her utility, $u$. Let $u_{j}$ be the utility which a randomly selected customer places on the purchase of one unit of brand $j$. Each brand $j$ 's position is defined by the amount of attribute 1 obtainable from one unit of brand $j, Q_{1 j}$, and the amount of attribute 2 obtainable from one unit of brand $j, Q_{2 j}$. The utility a customer places on one unit of brand $j$ is noted as $\tilde{u}_{j}$, which is a random variable to reflect customer heterogeneity. We define

$$
\tilde{u}_{j} \equiv \frac{\widetilde{w}_{1} Q_{1 j}+\widetilde{w}_{2} Q_{2 j}}{P_{j}}
$$

where we follow the original defender model by using $\widetilde{w}_{k}$ as the weight a customer places on attribute $k$ and $P_{j}$ denoting the price of brand $j$. In a market where the customer finds more than one brand available he or she decides to purchase the brand closest to his or her preferences. The probability that a randomly chosen customer chooses brand $j$ is denoted as $m_{j}$. It is defined as

$$
m_{j} \equiv \operatorname{Prob}\left[\tilde{u}_{j}>\tilde{u}_{i} \text { for all } i \neq j\right]
$$

where Prob[·] is a probability function. From (1) and (2) it follows that

$$
m_{j}=\operatorname{Prob}\left[\frac{\widetilde{w}_{1} Q_{1 j}+\widetilde{w}_{2} Q_{2 j}}{P_{j}}>\frac{\widetilde{w}_{1} Q_{1 i}+\widetilde{w}_{2} Q_{2 i}}{P_{i}}\right]
$$

or, after some algebraic manipulation,

$$
m_{j}=\operatorname{Prob}\left[\left(\frac{Q_{1 j}}{P_{j}}-\frac{Q_{1 i}}{P_{i}}\right)>\frac{\widetilde{w}_{2}}{\widetilde{w}_{1}}\left(\frac{Q_{2 i}}{P_{i}}-\frac{Q_{2 j}}{P_{j}}\right)\right]
$$

Hence, in a two-attribute space, the preferences of each customer can be represented by $\left(\widetilde{w}_{2} / \widetilde{w}_{1}\right)$ which is a sufficient parameter for computing choice probabilities. We define $\tilde{\alpha} \equiv \tan ^{-1}\left(\widetilde{w}_{2} / \widetilde{w}_{1}\right)$ which represents a measure of consumer preference that varies between 0 and $\pi / 2$. Figure 1 illustrates a randomly chosen customer's preferences who is indifferent between brand $i$ and brand $j . \tilde{\alpha}$ is the angle shown below in Figure 1. Any customer will naturally favor the brand that maximizes his or her utility. In Figure 1, customers whose indifference curve is steeper would prefer $j$ to $i$ while customers whose indifference curve is flatter would prefer $i$ to $j$. 


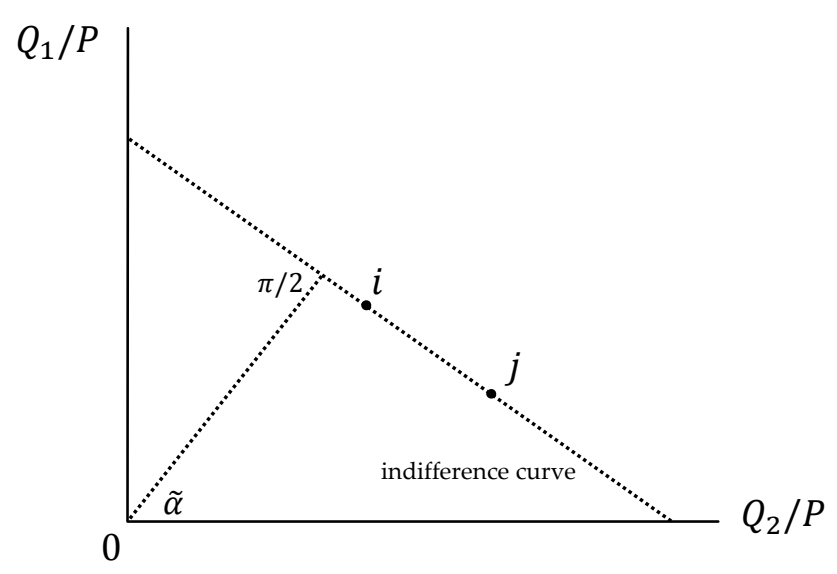

Figure 1: Geometric Illustration of a randomly chosen customer's preferences

For the sake of simplicity, we assume customer preferences to be uniformly distributed, i.e.

$$
\tilde{\alpha} \sim U\left(0, \frac{\pi}{2}\right)
$$

\subsection{BRAND POSITIONING AND MARKET SHARE}

We start with the initial market equilibrium with only one firm being active in the market, offering brand $I$. The brand's position in the two-attribute space is defined by its perceived attribute levels $\left(Q_{1 I}, Q_{2 I}\right)$ and its unit price $\left(P_{I}\right)$. In the initial situation, the monopolist serves the entire market. Consider a second firm $A$ deciding on its position in the two-attribute space and entering the market. Intuitively, in order to be positioned profitably, it will set quality levels and price such that its brand is positioned within the shaded areas in Figure 2 on the upper left or lower right of the monopolist's brand. ${ }^{3}$ Hence, there is a restriction on the second brand's positioning,

$$
\left(\frac{Q_{1 I}}{P_{I}}-\frac{Q_{1 A}}{P_{A}}\right)\left(\frac{Q_{2 I}}{P_{I}}-\frac{Q_{2 A}}{P_{A}}\right) \leq 0,
$$

which implies that each of the two firms' products has a "strong" and a "weak" quality dimension. Product characteristics are substitutive, i.e. both characteristics cannot be at their maximum at the same time. Qualities are normalized such that

$$
\max \left(Q_{1}\right)=\max \left(Q_{2}\right)=1
$$




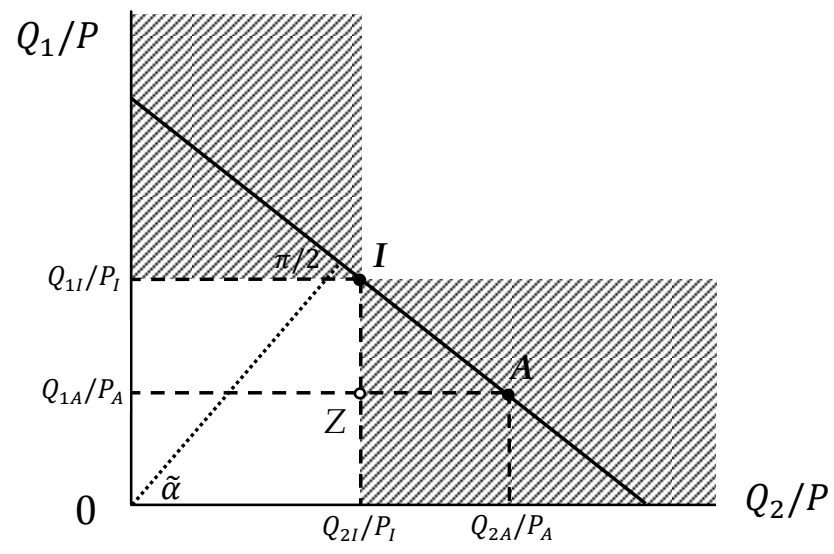

Figure 2: Positioning and Market Shares

Figure 2 illustrates an attack by brand $A$ which is represented by point $A$. The straight line with slope

$$
r \equiv \frac{Q_{1 A} / P_{A}-Q_{1 /} / P_{I}}{Q_{2 A} / P_{A}-Q_{2 l} / P_{I}}
$$

which represents the indifference curve of the customer that is precisely indifferent between brands $I$ and $A$. All customers with a steeper indifference curve than the one shown will choose brand $A$; those with a flatter indifference curve will opt for brand $I$. As we assume customer preferences to be uniformly distributed, the ray from the origin that intersects this indifference curve orthogonally now segregates the market in the shares attained by brands $I$ and $A$. The incumbent's market share is thus given as

$$
m_{I}=\left\{\begin{array}{c}
\frac{2}{\pi} \arctan (-r) \text { if } \frac{Q_{1 I}}{P_{I}}-\frac{Q_{1 A}}{P_{A}}>0 \\
1-\frac{2}{\pi} \arctan (-r) \text { if } \frac{Q_{1 I}}{P_{I}}-\frac{Q_{1 A}}{P_{A}} \leq 0
\end{array}\right.
$$

Market share $m_{A}$ can be computed and $1-m_{I}=m_{A}$. Total market size is assumed constant and equal to $N$. Hence, a brand $j^{\prime}$ s total sales volume is $N m_{j}$.

\subsection{ATTRIBUTES}

A feasible application of the defender model to any market requires a meaningful selection of quality attributes. Three conditions have to be met: First, the attributes have to affect the buying decision of customers, i.e. have to be relevant. Second, they are substitutive in nature. ${ }^{4}$ This ensures (a) that no brand can have high characteristics in all attributes at the same time and (b) each brand has to be positioned efficiently as no customer will chose a brand that is inferior to another in all attributes (shaded area in Figure 2). Third, the attributes have to be measurable. Many qualitative attributes can possibly be deployed in the model, depending on the research objectives. In order to analyze the impact of market entry in regulated postal markets, it is useful to choose attributes that allow regulatory measures to be integrated into the model. This should grant additional insights into post-liberalization mar- 
ket dynamics. In this application, we employ the attributes area coverage of delivery $\left(Q_{1}\right)$ and end-to-end transit time $\left(Q_{2}\right)$. The normalization (7) of $Q_{1}$ and $Q_{2}$ means that $\left(Q_{1} / 100\right) \%$ of all households have to be served daily to the doorstep and that delivery speed reaches a score of $\left(Q_{2} / 100\right) \%$ with $100 \%$ meaning same day (express) delivery of all items.

\subsection{OPERATORS' PROFIT}

The production of a certain level of quality entails cost. We assume costs to be convex in quality. Functional forms are stylized to represent the costs incurred when providing wide area coverage and high delivery speed. For simplicity, we assume that $C\left(Q_{1}\right)$ is fixed (volume independent) cost due to fixed delivery routes. $C\left(Q_{2}\right)$ is variable cost. Total cost and profit for the two operators are defined as follows.

$$
\begin{gathered}
\text { Total Cost }=T C=C\left(Q_{1}\right)+C\left(Q_{2}\right)=f Q_{1}{ }^{b}+N m g Q_{2}{ }^{d}-N m c-F \\
\text { Profit }=\pi=N m P-\left(f Q_{1}{ }^{b}+N m g Q_{2}{ }^{d}\right)=N m\left(P-c-g Q_{2}{ }^{d}\right)-f Q_{1}{ }^{b}-F
\end{gathered}
$$

where $0 \leq Q_{1}, Q_{2} \leq 1$. Parameters $f, g$ govern the absolute cost level associated with the choices of $Q_{1}$ and $Q_{2}$, while $b, d>1$ determine the convexity of the cost functions. Parameter $c$ is general marginal cost while $F$ is fixed cost.

\section{OPTIMAL PRICING AND POSITIONING REACTION}

The contribution proceeds with a two-step game describing an incumbent's optimal marketing response to market entry.

The sequence of decisions is shown in Figure 3.

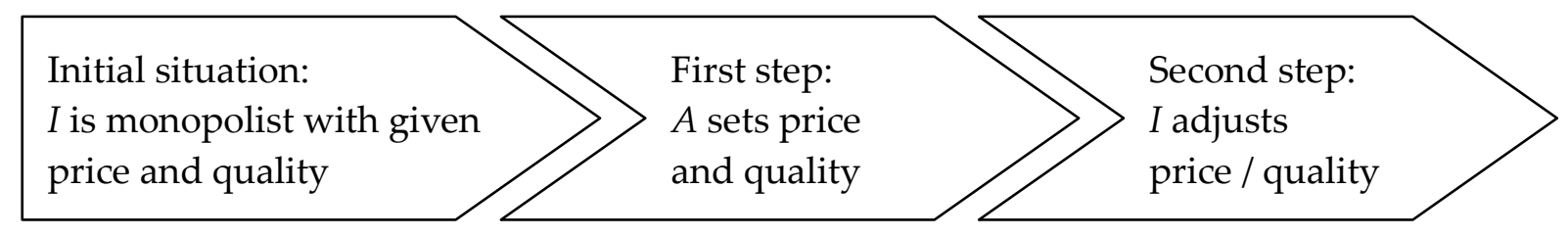

Figure 3: Sequence of decisions

In the initial situation, the incumbent serves the entire market. As a monopolist, its positioning strategy has to account for regulatory limitations. One limitation a USP is bound to is the offering of a wide-area coverage with doorstep delivery - this means it cannot choose the level of accessibility freely. Then, another service provider will enter the market by choosing its quality characteristics $Q_{1}$ and $Q_{2}$. Naturally, the attacking brand is positioned such that it attacks the defending brand's weaker attribute. With this product differentiation strategy, the new brand serves a significant share of the market leading to a decrease in profits for the incumbent. Strategically, the defending firm has two main options to defend its profits: adjusting price or differentiation by altering its product attributes. 
From (11) it follows that the incumbent maximizes its profit function:

$$
\pi_{I}=N m_{I}\left(P_{I}-c-g Q_{2 I}^{d}\right)-f Q_{1 I}^{b}-F
$$

There is no closed-form solution to the incumbent's optimal reaction to the entrant's attack. We therefore deduce its optimal reaction with numerical simulations. To do so, we proceed by comparing the competitive outcome to the incumbent's monopolistic profit before entry. In monopolistic mail markets, prices are assumed to be regulated by a price cap. It is plausible to assume regulated quality, too. Especially, coverage is regulated by a Universal Service Obligation (USO). We assume that both quality dimensions are regulated under the USO. With respect to quality $Q_{1}$, the USO prescribes ubiquitous delivery. Items may be delivered to P.O. boxes or postboxes near major routes, not necessarily to the receiver's doorstep. Hence, the USP is able to increase performance on this attribute in excess to what is prescribed in the USO. The USO in quality $Q_{2}$ prescribes a service with a minimum quality of $\mathrm{D}+3$.

We use stylized data and set a regulated price of $P_{I}=2.00$ and quality levels of $Q_{1 I}=0.8$ and $Q_{2 I}=0.4$, respectively. This implies that area coverage $Q_{1}$ is the incumbent's strong quality characteristic. This is also the quality attribute causing fixed costs. The other variables are set as follows: $c=F=0, N=100, f=50, g=3, b=3.0$ and $d=3.0$. In this setting, the simulation predicts that the incumbent would optimally position itself by providing minimum quality and charging maximum price. Hence, all regulatory restrictions are binding. The incumbent's profit before entry amounts to 155.20 .

\subsection{DEFENSE BY ADJUSTING PRODUCT ATTRIBUTES}

We assume first that the incumbent is allowed to react to the entrant's attack by adjusting its attribute $Q_{1}$ only, i.e. the strong quality dimension. With an optimal response, the incumbent can minimize losses compared to the initial situation. Simulating several possible attacks $\left(P_{A}, Q_{1 A}, Q_{2 A}\right)$ given the incumbent's regulated price $P_{I}$ and regulated quality $Q_{2 I}$ yields the results as in Table 1. We simplify the analysis by assuming an attacker's price constant at a value of 1.8 , i.e. $10 \%$ below the incumbent's price.

\begin{tabular}{|l|r|r|r|c|c|c|c|r|r|r|}
\hline & \multicolumn{4}{|l|}{ Attack } & \multicolumn{1}{l|}{ Defense } & \multicolumn{3}{l|}{ Market Outcome } \\
\hline & $Q_{1 A}$ & $Q_{2 A}$ & $P_{A}$ & $Q_{1 \mathrm{I}}$ & $Q_{2 \mathrm{I}}$ & $P_{I}$ & $m_{I}$ & $\pi_{I}$ & $\Delta \pi_{I}$ (monop.) & $\Delta \pi_{I}$ (no reaction) \\
\hline Monopoly & - & - & - & 0.80 & 0.40 & 2.00 & $100 \%$ & 155.20 & $0.00 \%$ & $0.00 \%$ \\
\hline Competition & 0.50 & 0.50 & 1.80 & 0.90 & 0.40 & 2.00 & $73 \%$ & 95.53 & $-38.44 \%$ & $6.18 \%$ \\
\hline Competition & 0.40 & 0.60 & 1.80 & 0.88 & 0.40 & 2.00 & $65 \%$ & 83.49 & $-46.20 \%$ & $2.91 \%$ \\
\hline Competition & 0.20 & 0.80 & 1.80 & 0.81 & 0.40 & 2.00 & $56 \%$ & 74.38 & $-52.08 \%$ & $0.01 \%$ \\
\hline Competition & 0.60 & 0.40 & 1.80 & 0.87 & 0.40 & 2.00 & $87 \%$ & 123.11 & $-20.67 \%$ & $4.19 \%$ \\
\hline
\end{tabular}

Table 1: Incumbent's optimum reaction in quality dimension 1 (strong dimension)

Table 1 shows that if the incumbent is assumed to react with product attribute adjustments in its strong dimension only, it will always minimize its profit loss by increasing its own strength. For an incumbent USP bound by price and quality regulation it can therefore be 
optimal to increase area coverage in our example. The more intensely the entrant attacks (by choosing high quality), the more intense will also be the incumbent's reaction.

\begin{tabular}{|l|r|r|r|r|c|c|c|c|r|r|}
\hline & \multicolumn{4}{|l|}{ Attack } & \multicolumn{2}{l|}{ Defense } & \multicolumn{3}{l|}{ Market Outcome } \\
\hline & $Q_{1 A}$ & $Q_{2 A}$ & $P_{A}$ & $Q_{1 I}$ & $Q_{2 I}$ & $P_{I}$ & $m_{I}$ & $\pi_{I}$ & $\Delta \pi_{I}$ (monop.) $)$ & $\Delta \pi_{I}$ (no reaction) \\
\hline Monopoly & - & - & - & 0.80 & 0.40 & 2.00 & $100 \%$ & 155.20 & $0.00 \%$ & $0.00 \%$ \\
\hline Competition & 0.50 & 0.50 & 1.80 & 0.80 & 0.56 & 2.00 & $100 \%$ & 122.96 & $-20.77 \%$ & $36.67 \%$ \\
\hline Competition & 0.40 & 0.60 & 1.80 & 0.80 & 0.57 & 2.00 & $83 \%$ & 94.43 & $-39.15 \%$ & $16.39 \%$ \\
\hline Competition & 0.20 & 0.80 & 1.80 & 0.80 & 0.47 & 2.00 & $60 \%$ & 75.83 & $-51.14 \%$ & $1.96 \%$ \\
\hline Competition & 0.60 & 0.40 & 1.80 & 0.80 & 0.44 & 2.00 & $100 \%$ & 148.06 & $-4.60 \%$ & $25.30 \%$ \\
\hline
\end{tabular}

Table 2: Incumbent's optimum reaction in quality dimension 2 (weak dimension)

Table 2 displays the incumbent's reaction to attacks by adjusting its weak quality dimension $Q_{2 A}$ (transit time). A comparison to the results in Table 1 shows that the incumbent now has more room to react (starting from a low quality level) which results in a lower loss in market share compared to the monopoly situation. In some scenarios, the incumbent is even able to retain $100 \%$ market share. However, in order to fight off competition, it has to increase quality, which is costly, and sacrifice part of its monopoly profit.

\subsection{DEFENSE BY PRICE ADJUSTMENT}

In a third set of scenarios, we assume that the incumbent is allowed to defend its profits by adjusting price instead of quality attributes. Table 3 shows that it is optimal for the incumbent to decrease its price in order to defend its market share. This result is not surprising; it can be observed in most markets where competition increases (see e.g. Ambrosini et al., 2011).

\begin{tabular}{|l|r|r|r|c|c|c|r|r|r|r|}
\hline & \multicolumn{4}{|l|}{ Attack } & \multicolumn{1}{l|}{ Defense } & \multicolumn{2}{l|}{ Market Outcome } \\
\hline & $Q_{1 A}$ & $Q_{2 A}$ & $P_{A}$ & $Q_{1 \mathrm{I}}$ & $Q_{2 \mathrm{I}}$ & $P_{I}$ & $m_{I}$ & $\pi_{I}$ & $\Delta \pi_{I}$ (monop.) & $\Delta \pi_{I}$ (no reaction) \\
\hline Monopoly & - & - & - & 0.80 & 0.40 & 2.00 & $100 \%$ & 155.20 & $0.00 \%$ & $0.00 \%$ \\
\hline Competition & 0.50 & 0.50 & 1.80 & 0.80 & 0.40 & 1.66 & $88 \%$ & 104.53 & $-32.65 \%$ & $16.18 \%$ \\
\hline Competition & 0.40 & 0.60 & 1.80 & 0.80 & 0.40 & 1.65 & $79 \%$ & 89.27 & $-42.48 \%$ & $10.03 \%$ \\
\hline Competition & 0.20 & 0.80 & 1.80 & 0.80 & 0.40 & 1.83 & $62 \%$ & 75.02 & $-51.66 \%$ & $0.88 \%$ \\
\hline Competition & 0.60 & 0.40 & 1.80 & 0.80 & 0.40 & 1.80 & $100 \%$ & 135.20 & $-12.89 \%$ & $14.42 \%$ \\
\hline
\end{tabular}

Table 3: Incumbent's optimum price reaction

Comparing the scenarios with quality repositioning and price adjustment indicates that the possibility to react on the weak quality dimension is most valuable to the incumbent. Hence, quality adjustment in this dimension dominates a reaction in price. From the comparison of the three tables it can also be concluded that with our assumptions of a fixed and a variable cost attribute, a low-price attack on the variable cost attribute - as often seen in liberalized network markets - harms the incumbent the most. However, it can be dampened both by lowering prices or strengthening own product quality. 
If the incumbent is only able to adjust its strong quality attribute, competing at the price margin is more profitable. If the incumbent is able to react on its weak quality dimension, however, it should rather do so instead of entering a price war. Of course, this result depends on the possibility of the incumbent to actually react on the quality margin. This may not be an option in all quality dimensions with binding USO in place which sets some attributes extremely high.

Concluding from the competitive situation in the Swedish postal market with selective market entry in the low-quality mail segment, Cohen et al. (2007) find that "the primary response of incumbents when confronted with significant competition will be to embark on a stringent cost reduction program, establish cost and volume based prices, and compete vigorously for large customers through aggressive negotiated prices". This is also what airlines and banks did when competition first arose. More creative competitors then showed them that there are other quality attributes that were not being paid attention. In the postal sector, these may include improved billing procedures, and customer account management, increased flexibility and hours of operation, date certain delivery and many more.

\section{SUMMARY AND CONCLUSION}

Mail markets have recently been opened up to competition in most European countries. Market entry will force incumbent postal operators to (re-)position themselves strategically. In this paper we analyzed the strategic competition between incumbent postal operators and market entrants in liberalized letter markets based on the "defender consumer model" pioneered by Hauser and Shugan (1983) and derived qualitative normative implications on how an established firm should defend its profits when facing an attack by a new competitive product.

Our results extend the literature on competition in liberalized mail markets by combining pricing and positioning strategies from a marketing perspective. Our analysis based on the defender model highlights that incumbent postal operators can defend their market shares by differentiating their services along one or more quality dimensions. Postal services are not necessarily homogenous. If postal operators focus solely on pricing strategies they will run into the more serious problems than if they compete on quality too.

Examples from other industries such as the airline industry have shown that differentiation is essential for the success of individual firms and the industry as a whole. Postal operators can also segment the market and escape the vicious circle of price competition. So far, incumbent postal operators have little experience in developing differentiation strategies. Moreover, as Kleindorfer and Szirmay (2009) have highlighted, many incumbent operators do not have strategy and marketing departments with the necessary knowledge to analyze consumer preferences and optimal brand positioning in the digital age and with increasing competition. 
Our analysis highlights the importance of these strategies and explains the basics of important analytical tools in this field. The model is potentially quite general and able to represent several forms of competition in the market for mail. In principle, even intermodal competition can be modeled. However, to this end, additional quality dimensions would have to be introduced because E-Mail is superior to letter mail in both quality dimensions modeled.

Similarly, the effect of various USO specifications can be taken into account. This would allow for a calculation of the net cost of the USO according to the established profitability approach in an entirely different model environment than the ones applied before (see e.g. Jaag and Trinkner, 2011). We leave these extensions to our analysis to future research.

\section{NOTES}

1. In some industries, a delayed reaction could as well be explained by signaling reasons (See Kalra et al., 1998).

2. These are: Representation by a product position, utility maximization and linearity (see Hauser and Shugan, 1983, p. 321ff.)

3. A position in the upper right of the incumbent would result in the entire market being served by the entrant while if positioned in the lower left, the entrant would attract zero market share.

4. In the original paper, the authors chose for liquid dish washing detergents the attributes efficacy and mildness. They are relevant to the customers and they meet the condition of substitutability.

\section{REFERENCES}

Ambrosini, X., S. Bréville, J. Cornée and O. Klargaard (2011). Pricing Strategies in Regulated Markets - Innovative pricing in the postal sector. Competition and Regulation in Network Industries 12, pp.57-82.

Bowman, D. and H. Gatignon (1995). Determinants of Competitor Response Time to a New Product Introduction. Journal of Marketing Research, 32(1), pp.42-53.

Cohen, R., P. Jonsson, M. Robinson, S. Selander, J. Waller, S. Xenakis, (2007). The Impact of Competitive Entry into the Swedish Postal Market. Paper presented at the WIK 10th Königswinter Seminar on "Postal Markets between Monopoly and Competition".

Crew, M. A. and P. R. Kleindorfer (2001). Whither the USO under Competitive Entry: A Microstructure Approach. In: Crew, M. A. and P.R. Kleindorfer (eds), Future Directions in Postal Reform. Boston, Mass.

Crew, M. A. and P. R. Kleindorfer 2007. Approaches to the USO under Entry. In: Crew, M. A. and P.R. Kleindorfer (eds), Liberalization of the Postal and Delivery Sector, Edward Elgar Publishers, Cheltenham, UK. 
Dietl, H., U. Trinkner and R. Bleisch (2005). Liberalization and regulation of the Swiss letter market. In: Crew, M. A. and P.R. Kleindorfer (eds), Regulatory and Economic Challenges in the Postal and Delivery Sector. Boston, Mass.

Dietl, H. and P. Waller (2002). Competing with Mr. Postman: Business Strategies, Industry Structure, and Competitive Prices in Liberalized Letter Markets. Schmalenbach Business Review 54, pp.148-170.

Hauser, J. and S. Gaskin (1984). Application of the "Defender" Consumer Model. Marketing Science, 3(4), pp.327-351.

Hauser, J. and S. Shugan (1983). Defensive Marketing Strategies. Marketing Science, 2(4), pp.319-360.

Hauser, J. and S. Shugan (2008). Commentary. Defensive Marketing Strategies. Marketing Science, 27(1), pp.85-87.

Hauser, J. and P. Simmie (1981). Profit Maximizing Perceptual Positions: An Integrated Theory for the Selection of Product Features and Price. Management Science, 27(1), pp.33-56.

Heil, O. and R. Walters (1993). Explaining Competitive Reactions to New Products: An Empirical Signaling Study. Journal of Product Innovation Management, 10(1), pp.53-65.

Jaag, C. (2007). Liberalization of the Swiss Letter Market and the Viability of Universal Service Obligations, Swiss Journal of Economics and Statistics, 143(3), pp.261-282.

Jaag, C. and U. Trinkner (2011). The interaction between universal service costing and financing in the postal sector: a calibrated approach, Journal of Regulatory Economics 39(1), 89-110.

Kalra, A., S. Rajiv and K. Srinivasan (1998). Response to Competitive Entry: A Rationale for Delayed Defensive Reaction. Marketing Science, 17(4), pp.380-405.

Hotelling, H. (1929). Stability in Competition. The Economic Journal, 39(153), pp.41-57.

Kleindorfer, P. R. and Z. Szirmay (2009). Pricing practice in the postal industry: current approaches and challenges under liberalization, Research paper, INSEAD \& Roland Berger.

Kuester, S., C. Homburg, T. Robertson and H. Schaefer (2001). Verteidigungsstrategien gegen neue Wettbewerber. Bestandsaufnahme und empirische Untersuchung. Zeitschrift für Betriebswirtschaft, 10.

MacMillan, I., M. McCaffery and G. Van Wijk (1985). Competitors' Responses to Easily Imitated New Products - Exploring Commercial Banking Product Introductions. Strategic Management Journal, 6(1), pp.75-86. 
Shugan, S. (1987). Estimating Brand Positioning Maps Using Supermarket Scanning. Journal of Marketing Research, 24(1), pp.1-18.

Shankar, V. (1999). New Product Introduction and Incumbent Response Strategies: Their Interrelationship and the Role of Multimarket Contact. Journal of Marketing Research, 36(3), pp.327-344.

Urban, G. and J. Hauser (1980). Design and marketing of new products. Englewood Cliffs, NJ: Prentice-Hall. Urban, G.L. and G.M. Katz. 